\title{
Optimal Slewing Mode Converter-based Energy Management System for Renewable Energy sources
}

\author{
S. Rajalakshmi ${ }^{1}$, Dr S.Titus ${ }^{2}$ \\ ${ }^{1}$ Assistant Professor, Department of EEE, University College of Engineering, BIT Campus, India. \\ *rajalakshmiphd17@outlook.com \\ ${ }^{2}$ Professor, Department Of EEE, K.Ramakrishnan College of engineering Samayapuram, India.
}

\begin{abstract}
Nowadays, the trade-off between the generation and distribution is the major requirement to meet out the high-demand scenario. Hence, the energy crisis is considered as the major significant research area in the developed countries around the world. The evolution of Renewable Energy Sources (RES) such as solar, wind are considered as the major topologies for the pollution-free environment. The deployment of inverter-converter topologies into the hybrid vehicle applications assures the stable output power levels across the load. Because of the climatic conditions, uncertainties, harmonics (due to the non-linear loads), the output voltage levels and energy levels are disturbed. To alleviate such issues, the bi-directional converter is evolved in research studies. The proper control topology is the major requirement for the controllable voltage generation and hybrid energy storage across the loads. This paper proposes the optimal slewing mode converter (OSMC) topology which generates the gate control signals to the switches present in the Bi-directional Converter (BC). In proposed methodology input is PV source and the SOS MPPT algorithm is employed for regulating the charge of battery. The utilization of current control function for the pulse generation assures the dynamic response and the robustness in the energy storage systems irrespective of the climate conditions. The integration of frequency sector and periodic sector controllers to the bidirectional converter with the optimization results in dynamic power regulation and battery stress. The simulation in both time and frequency sectors investigates the performance of proposed topology in hybrid energy storage applications.
\end{abstract}

Key words : Bidirectional, Current Control Function, DC-DC boost converter, Energy Storage System, Frequency Divider, Inverter.

\section{INTRODUCTION}

Recently, world energy crisis is the significant research problem around the various countries in the world which promotes the Building Integrated Photovoltaic (BIPV)[1] applications. The utilization of less-cost renewable energy to generate pollution-free electricity is the major criteria for such promotion. With this criteria, the seamless integration BIPV with the buildings is the major requirement in order to reduce the installation cost and minimize the energy payback time respectively[2]. The ground and roof-based PV systems are the two types of environment in BIPV. Among them, the ground-based PV modules operate based on the identical irradiance. But, the installation of PV modules in diverse orientation and angles violate the irradiance conditions. Hence, the energy efficiency depletion is the major consideration in PV panel installation. The wide utilization of fossil fuels caused the greenhouse gas emission which induces the pollution to the environment. Hence, the energy crisis focuses on the development of renewable energy such as solar or wind. The voltage obtained from the solar panels must be converted into the AC for the home appliances. In general, the bridge-type DC-AC inverter is used in the grid connected PV system. But, the employment of such inverter without the isolation transformer results in leakage current. Hence, the novel DC-DC boost converter with the coupling topologies to provide the negative grounding and the leakage current.

The connection among the renewable energy resources and the utility grid is governed by an interface namely Pulse Width Modulation (PWM) inverters[3]. The diversity among the grids requires the various types of inverters with the different power, frequency and phase levels of either voltage or current sources. The provision of proper gate signals controls the output voltage of the inverter which assures the stability of the grid. The adjustments of amplitude, phase and frequency of the fundamental component according to the carrier signal (modulation) generates such gate control signals for power semiconductors. The modulation techniques offer the better solution to the two-level power converters[4]. The PWM is a simple modulation technique to produce a pulse voltage (or) current waveform with the equal time average with the reference signal. The presence of non-linear loads produces the harmonics which are additional components to the fundamental component. The incorporation of LCL filter design[5] provides the great attenuation to the higher-order harmonics under lower switching frequencies. But, the peak value at resonant frequency causes the oscillations which leads to unstable 
state. Hence, the controller must be properly designed to alleviate the stability issues.

Due to the existence of good mathematical models, input and output variables in both mechanical and electrical systems, the Model Predictive Control (MPC)[6] has the dramatic advance topology in the automatic controlling applications. The promising current control scheme in order to compensate the harmonic distortion due to non-linear loads is the design of Active Power Filters (APFs)[7]. But, the lack of exact compensation of periodic signals with the frequency variations in Repetitive Control (RC) scheme degrades the performance of APF. The input and output voltage variations are represented by the set of non-linear equations in offline mode. But, these equations have the multiple solutions to represent the output line-to-line voltages. Under some fault conditions, the non-linear equations provide no solutions which required an extension of the neural shift method. In this method, the angle between the two voltages must be 180 degree with the modulation index adjustments to assure the optimization of output line-to-line voltages.

With an emerging new trends and uncertainties in power systems, the automatic generation and control is the most significant scheme by considering the problem called Load Frequency Control (LFC)[8]. The major objective of the LFC problem handling scheme is to maintain the stability performance under the various disturbance conditions. To ensure the frequency stability maintenance and assure the smoothening of output voltage, Battery Energy Storage (BES) systems are evolved. These systems require the proper coordination among the distributed energy resources to smooth out the power fluctuations in the feeder lines. The utilization of distributed generations and the controlling of output voltages across the loads achieved such co-ordination. The introduction of the Distributed Energy Restorers (DER) with the controllable loads provided the energy efficient storage systems in demand conditions.

Regulation of power generated from the wind turbines requires the advanced Back-to-Back (BTB) converters [9] with the full power extraction capabilities. Reduction of stress and the increase in energy generation states the importance of power electronics in the power regulation. The integration of wind power into the grid requires the incorporation of power electronic switches with the control signals. But, the high-efficiency energy demanding with the robust cost developed models requires the minimum amount of filters. The closed loop control schemes are not suitable for the on-off controlling of phase angles of input and output voltage which raise the bidirectional converters usage. The major benefit of the bidirectional converter is the efficient regulation capability against the changes in weather condition or battery size. The mode in which the bidirectional inverter injects the power to the AC grid under the high PV power conditions is referred as grid connection mode[10]. Conversely, the mode in which the compensation of load added to the system through the power drawn from the AC grid is referred as rectification mode. The general review of power electronic topologies in this introduction section conveys that the refinement in the control topologies is required to maintain the stable output voltage across the grid. The technical contributions of proposed work are listed as follows:

- The proposed optimal slewing mode controller (OSMC) generates the control signals for the switches present in the bidirectional converter. The provision of optimal switching instants for the pulse generation maintains the energy stability across the loads

- The current controlled pulse generation from the OSMC provides the robustness in hybrid energy storage and the dynamic power regulation irrespective of the climate changes and the uncertainties due to loads.

- The construction of bi-directional converter with the slewing mode controller is responsible for controlling the pulse density to the switching device to mitigate the battery damages caused by the charging and discharging currents. The paper organized as follows: The detailed description about the related works on controlling strategies of bidirectional converter is presented in section II. The implementation process of proposed Optimal Slewing Mode Controller (OSMC)-based Bidirectional Converter (BC) is described in section III. The performance of proposed OSMC-BC is investigated against the existing algorithms with the various performance parameters in section IV. Finally, the conclusions about the application of proposed controlling topologies on voltage regulation are presented in section $\mathrm{V}$.

\section{RELATED WORK}

In this section, the brief review of the issues in the existing control topologies for bidirectional converters is presented in detail with their limitations. Wu, et al[11]designed a single-phase bidirectional inverter with two buck/boost maximum power point trackers (MPPTs) corresponding to the DC-distribution applications. The employment of a droop regulation mechanism based on the current levels reduces the capacitor size and balances the power flow in order to accommodate the load variations respectively. Wu et al[12] extended the above topology to the D- $\Sigma$ digital control with the filter-capacitor-current compensation. The derivation of the control laws and the analysis of grid current harmonics were presented. With these laws, the high phase margin among the output and grid impedance was achieved from low to high frequencies. The high impedance phase margin also achieved the high-harmonic rejection ratio $\left(39^{\text {th }}\right)$ which was suitable in efficient grid connection. Chen et al[13] proposed the floating active switch-based converter for the isolation of energy level from the PV panel under AC module is in OFF condition. This type of topology offered the intensive protection of installers and users from electrical hazards. An effective recycling of inductor energy to the load and the attainment of high-step-up voltage conversion ratio explained the high-performance of the modules. Xuewei et al[14] proposed the novel switching soft switching push-pull converter to reduce the gating requirement under common 
ground conditions. The natural clamping of device voltage based on the secondary modulation by the passive snubbers achieved the Zero Current Switching (ZCS) and Zero Voltage Switching (ZVS) of the secondary devices. Wang et al[15]proposed the novel frequency control topology on the basis of the double Sliding Mode (SM) for the integration of renewable sources with the grids. The secondary frequency regulation was achieved by the construction of SM load frequency controller (LFC). Besides, the system frequency was restored to normal with the secondary frequency regulation.

Ribeiro et al[16] presented the robust adaptive control strategy which was integrated to the variable control scheme for the APF topologies to provide the balance among the power and energy levels. Merai et al[17]investigated the implementation of the Field Programmable Gate Array (FPGA)-based Space-Vector Delta Modulation Current Controller (SV-DMCC) to improve the performance of three-phase Grid connected Converters (GcCs). On the basis of sliding mode theory, the synthesis of the SV-DMCC in the stationary reference frame $(\alpha, \beta)$ was performed. The accurate selection of voltage vectors reduced the current errors across $\alpha$ and $\beta$ axis. Due to the minimization of errors in the current vectors, the harmonics and the execution time were reduced to the certain level. Vazquez et al[18] presented the Optimal Switching Sequence Direct Power Control (OSS-DPC) algorithm from the predictive control family that provided desired power reference levels effectively. Besides, they also introduced the reduced OSS-DPC (ROSS-DPC) to address the computational and implementation issues respectively. Flores et al[19]designed the robust nonlinear adaptive controller for trajectory tracking in maximum phase output voltage against the time-varying conditions respectively. The exploitation of flatness property in the proposed Generalized Proportional Integral (GPI) indirect control provided the fast adaptations and achieved the effectiveness against the plant uncertainties. Liu et al[20]proposed an Extended State Observer (ESO) based second-order sliding-mode (SOSM) control technique which focused on the input current-based tracking of the desired values, which offered the voltage regulation indirectly. The interconnection of load with the DC-link capacitor (external disturbance) was rejected by the ESO-SOSM.

Kanjiya et al[21]proposed a single-step non-iterative optimized algorithm for the APF topologies under the unbalanced supply conditions. The optimal determination of conductance factors and the provision of average power-balance constraints were the major objectives of optimized algorithm. Due to the absence of complex iterative optimization, the algorithm was simple, fast and dynamic under dynamic load conditions. With these merits, the derivation of conductance vectors using the Lagrangian formulation separated the harmonics into odd and even effectively. Badoni et al[22]proposed a three-phase shunt active power filter (SAPF) to mitigate the power quality problems such as unbalancing, reactive power and harmonics observed in the distribution side. The elimination of harmonics assured the unity power factor and better voltage regulation. The utilization of a three-phase voltage-source converter (VSC) as the SAPF performed all the functions effectively. Moreover, the development of optimum filtering technique to extract the reference supply currents from the current effectively compared to the least mean square (LMS) adaptive filter-based control algorithm. Modi et al[23] analysed the comparison of sine-triangle-based PWM with the common mode injection PWM during over modulation under space vectors. The study of production of average voltage vector and the compared with the average voltage vector were highlighted. The utilization of single DC source provided the path for the zero-sequence currents which caused the distortion. Kumar and Sivakumar[24]minimized the zero-sequence currents which flow through the motor phase which affected the harmonics. As this configuration uses a single dc source, it provides a path for zero-sequence currents because of the zero-sequence voltages present in the output, which will flow through the motor phase winding and power electronic switches. To minimize these zero-sequence currents, sine-triangle pulse width modulation (SPWM) was used which shifted the lower order harmonics near to switching frequency in the linear modulation region. But, the generation of harmonic voltages close to the fundamental frequency in over modulation region required the modified SPWM technique which increased the modulation index to $2 /$ $\sqrt{3}$.Liu and Li[25]proposed the novel high step-up dc-dc converter with a quasi-active switched-inductor structure to restore the energy. The composition of two coupled inductors with the magnetic core achieved the high step up gain with the optimal duty cycle ratio. The utilization of the two diode capacitor circuits helpful to increase the voltage conversion gain with the alleviation of voltage spikes due to the leakage inductance which limited the voltage stress across the switches. The review of traditional studies conveyed that the charging/discharging currents in short timescale increased the bandwidth limit and the corresponding current lead to the damage in battery and thus the lifetime was minimum. This paper proposes the novel control strategy to alleviate such issues observed in the existing system.

\section{PROPOSED OPTIMAL SLEWING MODE CONTROL-BASED ENERGY MANAGEMENT SYSTEM}

This section discusses the implementation of proposed Optimal Slewing Mode Control (OSMC) for controlling the voltage signals to the gate of the switches participated in the bidirectional converter used to store the energy and reduce the battery damages. Fig. 1 shows the workflow of the proposed OSMC modeling for the regulation of charging and discharging currents. 


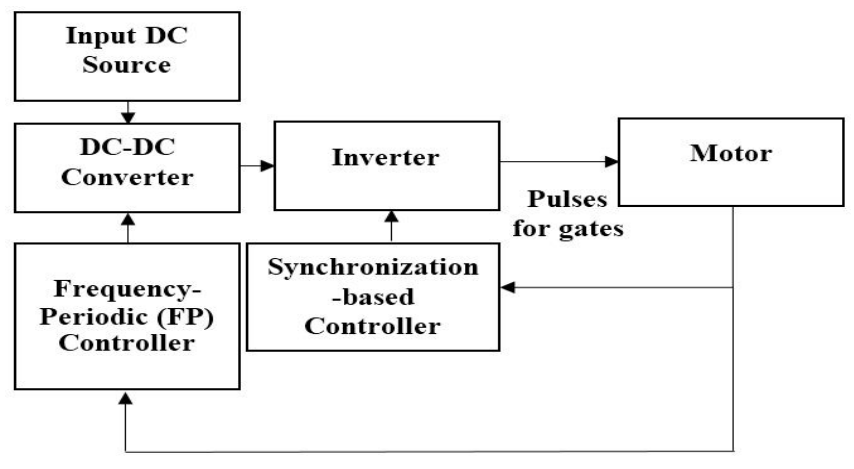

Figure 1: Overall flow of OSMC

The workflow comprises major sections control system 1 and 2 for the converter and inverter circuits. Initially, PV source is passed to the DC-DCboost converter section. PV panel is considered and are fed to the circuit system for the efficient storage of power system. The MPPT control mechanism is considered for regulating the charge of battery. By means of the calculation and deliberation of mathematical models and ideal switches of all components, the efficiency is computed in spite of real models. The MPPT decreases in the PV module characteristic with the increase in the level of temperature. Similarly, the MPPT increases with increase in the irradiance. After this, for boosting up the power, DC-DC converter is used. This can be helpful for the charging of battery automatically while the battery is in ON condition. The mathematical modeling of control systems generates the necessary control signals based on three modes such as traction mode, regeneration mode and the Ultra Capacitor (UC) energy recovery modes. The integration of frequency and periodic section controllerto the bidirectional converter is performed along with the optimization results in dynamic power regulation and battery stress in order to restore the energy and maintain the battery lifetime.

\subsection{Circuit Description}

The schematic representation of energy storage system contains three modules, battery unit, motor and UC. The power between the motor and battery is regulated through the switching combination of S1 and S8 as shown in Fig.2.

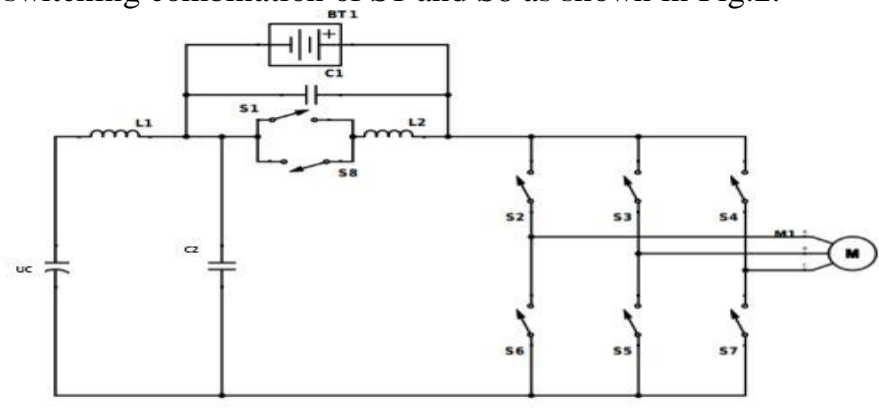

Figure 2: Basic circuit diagram

The proposed circuit contains inductors L1 and L2, capacitors (C1 and C2), inverter switches (S2 to S7), battery BT1 and the $\mathrm{UC}+$ switch (S1 and S8). Insulated Gate Bipolar Transistors (IGBT) which operate as the switches The major assumptions for the circuit operation are listed as follows:
- Ideal switching elements - Drop in forward voltage during the ON state is negligible.

- Equivalent series resistance of the capacitance and stray capacitances are negligible

- The characteristics of the passive elements employed in the circuit are assumed to be linear, time-invariant and the independent of frequency.

\subsection{Operating Modes}

The relationship between the capacitor voltage $\left(V_{\mathrm{C1}}\right)$ with the voltage of UC are expressed through the duty cycle $(D)$ as follows:

$V_{C 1}=\frac{D}{1-2 D} V_{U C}$

Similarly, the DC link and line voltage are expressed as

$V_{\text {bus }}=\frac{V_{L C}}{1-2 D}$

$V_{\text {line }}=\frac{\frac{1-2 D}{1-D}}{D} V_{\mathrm{C} 1}$

Where, $D$-Shoot through duty cycle ratio

The average power from the DC link is the combination of average power supplied by UC and battery with neglecting power loss is expressed as

$P_{\text {VC }}+P_{b}=P_{b u s}$

Similarly, the average current from UC, dc link and batteries are related by

$$
(1-2 D) I_{V C}+D I_{b}=I_{b u s}
$$

The power and the current routes decide the six operating modes for the proposed system.

Mode 1: S1 ON S8-OFF

In this mode, the motor gets supply from the UC and the battery. Then, the battery and the UC supplies the power to the circuit through this S1 switch. In this stage, the current in $\mathrm{L} 1$ and the voltage across $\mathrm{C} 1$ gets discharging which leads to discharging of current in L2 as shown in Fig.3 (a).

Mode 2:S1-OFF, S8-ON

During this operation mode, the inductor L2 gets charged by the combination of UC and battery. In this stage, $\mathrm{C} 2$ gets charged from the inductor L2 as shown in Fig. 3(b)

Mode 3: SI ON S8-OFF

In this mode, the motor supplies the power to the UC and the battery. Then, the motor energy is transferred to the battery, UC and L1-C2 combination. In this stage, the current in L1 and the voltage across $\mathrm{C} 2$ gets increasing as shown in Fig.3 (c)

\section{Mode 4:S1-OFF, S8-ON}

During this operation mode, the inductor L2 gets charged by the capacitor $\mathrm{C} 2$ and the energy is transferred to the battery and UC through the aL1 as shown in Fig. 3(d)

Mode 5: S1 ON S8-OFF

In this mode, the battery is turned on which supplies power to both UC and motor. In this stage, the inductor L1 acquire the energy from the capacitor C2 and L2 gets energy from battery as shown in Fig.3 (e).

Mode 6:S1-OFF, S8-ON

During this operation mode, the energy in the inductor L2 is transferred to $\mathrm{C} 2$. At this same stage, the power is delivered to UC+battery from the L1 as shown in Fig. 3(f). 


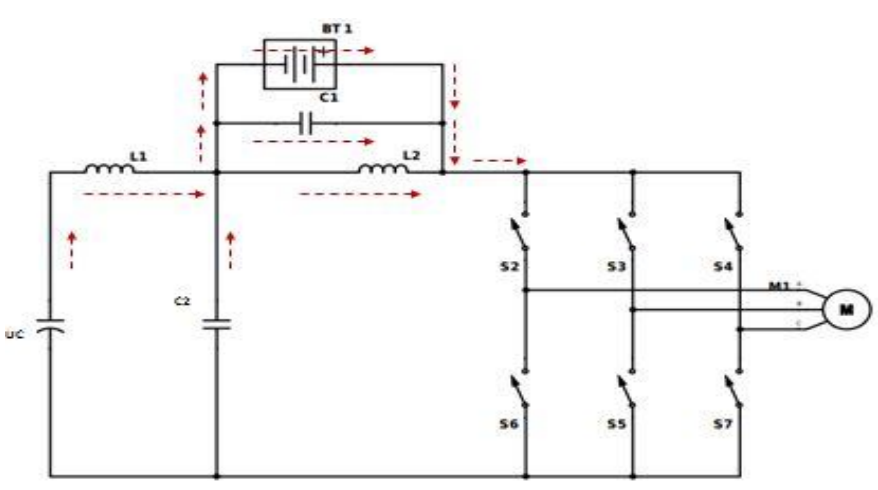

(a)

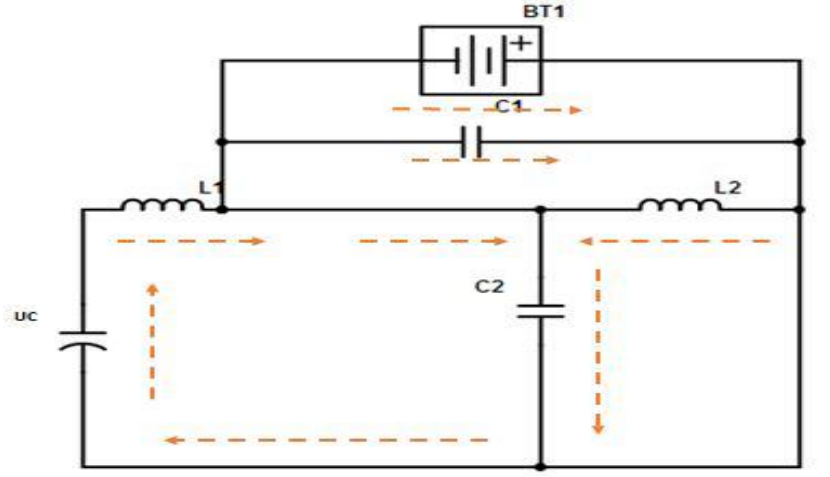

(b)

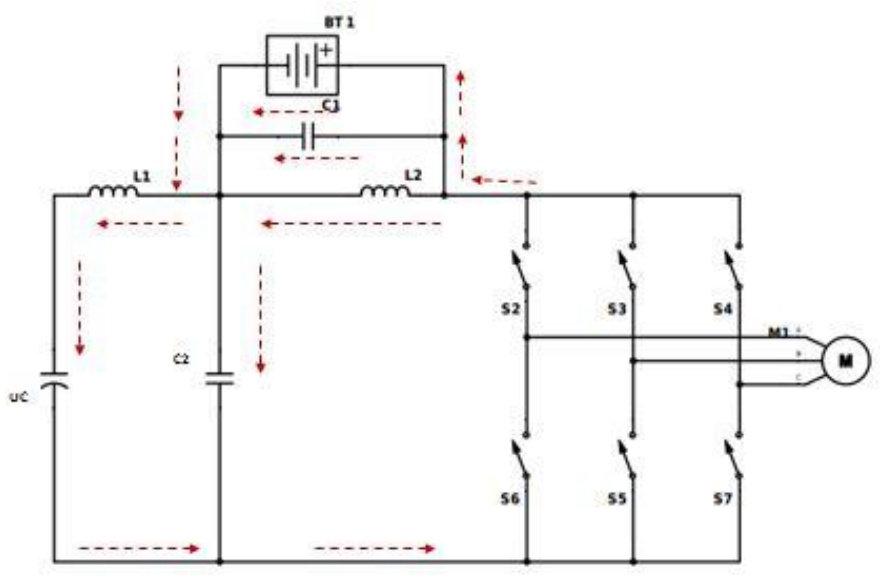

(c)

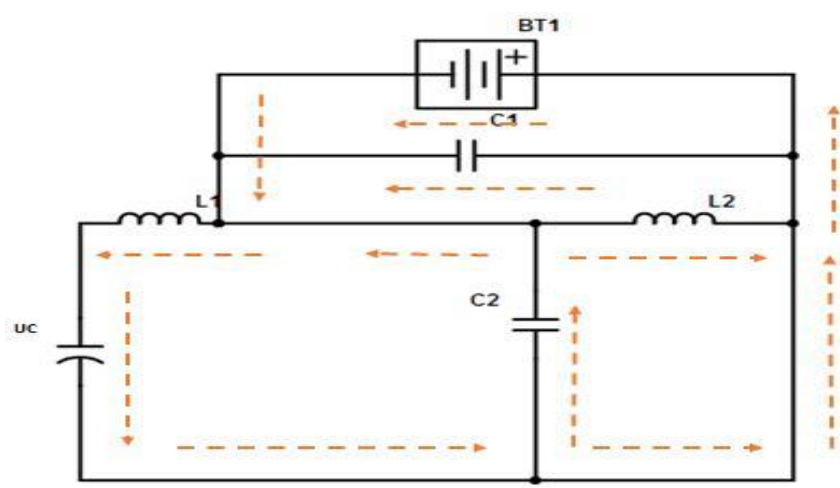

(d)

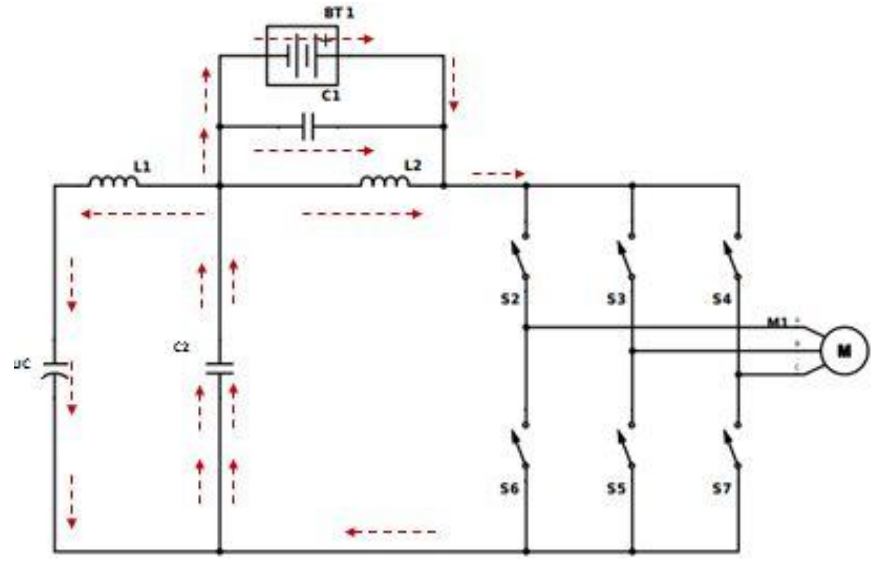

(e)

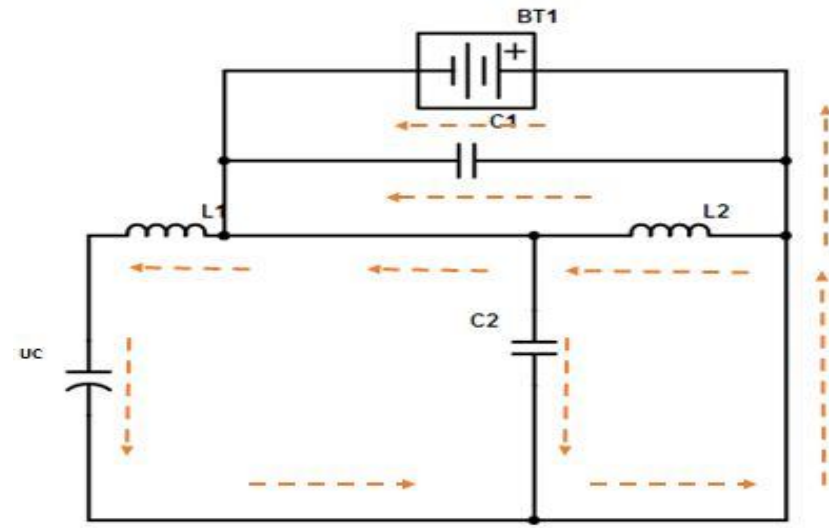

(f)

Figure 3: Operating Modes of OSMC-BC

The combination of mode 1 and 2 tracks the energy from the battery to the motor and hence they are called as tracking mode or forward mode. During mode 3 and 4, the reverse process of racking takes place such as motor acts as the source to the circuit. Hence, they are called as regeneration mode. Finally, the integration of mode 5 and 6recovers the energy from the battery and supplies them to the inductor capacitor combination. Hence, they are called as energy recovery modes.

\subsection{Proposed Controller Design}

The proposed controller includes three parts such as periodic and frequency sector controller and battery current regulation domain. There are two controller systems are employed in proposed work to provide the gate signals to the DC-DC converter and inverter. The utilization of complementary properties of the battery (BT1) +UC combination is the basic advantage in frequency section. In this stage, the high-frequency components are supported by the UC and low frequency components are governed by battery.

The current flow through the battery is shaped in periodic section and frequency section controllers. The basic objective of this domain is to ensure the battery to operate within the 
limits. The detail schematic representation of frequency and 2 is shown in Fig. 4 (a) and (b) respectively. Frequency-Periodic controller and synchronization controller includes the frequency dividing unit $\mathrm{S}_{\mathrm{f}}$, voltage restoration in $\mathrm{S}_{2}$. The peak current estimation and regulation unit gets operation state in periodic. Then, the battery current regulation and forward units are operated during the battery current regulator state.

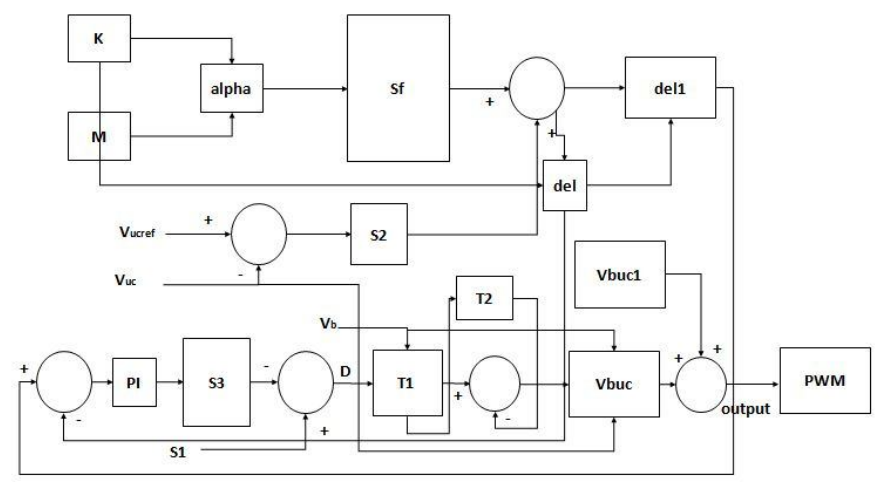

(a)

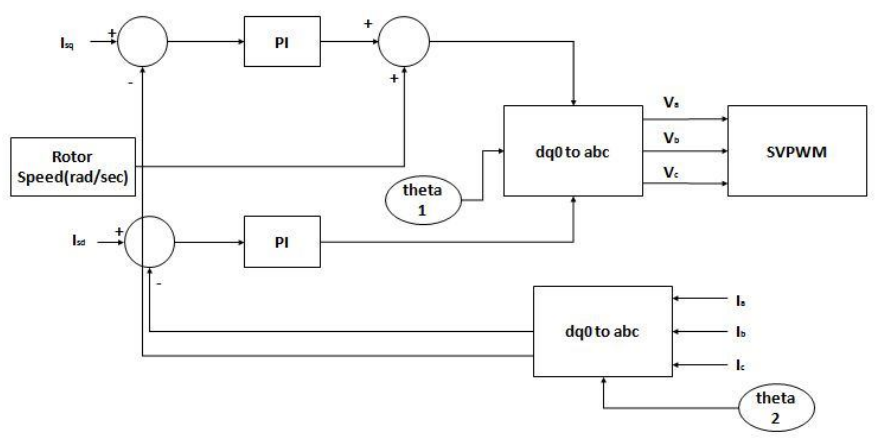

(b)

Figure 4: (a) Frequency-Periodic Controller and (b) Synchronization-based Controller.

The inputs to the frequency dividing unit comprises modulation index $(\mathrm{M})$ and the constant term $\mathrm{K}$ which are represented as

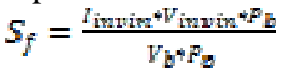

Where, $I_{\text {muin }}$ - Inverter input current

$V_{\text {invin }}$ - Inverter input voltage

$\boldsymbol{P}_{\mathrm{b}}$ - Battery power

$P_{0}$ - Output power

$V_{b}$ - Battery voltage

$M=\frac{\left(\sqrt{2} * q^{4} u_{r}\right)+\left(2 v_{b}\right)^{2}-\left(v_{u c}{ }^{2} y_{y}\right.}{\left(2 v_{b}+2 v_{u c}\right)}(7)$

Where, $\boldsymbol{M}$-modulation index

$\omega$ - Motor flux

$\omega_{r}-$ Rotor speed (rad/sec)

$V_{v c}$ - Voltage across the ultra capacitor

$K=I_{s q}+\left(\frac{F_{b}}{F_{b}}\right)$

Where, $I_{s q}$ - stator current in d-axis
The terms $K$ and $M$ are multiplied together to decide alpha $(\alpha)$ for the frequency divider $\left(S_{F}\right)$ as follows.

$a=K * M$

The inputs for the blocks $S_{1}, S_{2}$ and $S_{2}$ are modeled as follows in order to select the frequency for the current.

$S_{1}=\frac{v_{b}}{v_{j c}}$

$S_{2}=\left(1+\frac{R_{i}}{g}\right): \frac{1}{g}$

$S_{g}=M *\left[K_{F}\left(1+\frac{K_{h}}{g}\right)\right]$

$I_{f x}=S_{f}+S_{2}$

Where, $K_{F}$ - Proportional gain

$\kappa_{i}$ - Integral gain

Once, the frequency selection is over with the above formulations, then the periodic selection is enabled in the controller section. The equations governing the periodic are represented as follows:

$\delta=\left\{\begin{array}{cl}I_{f s} & K<0.5 \\ K * I_{f s} & \text { otherwise }\end{array}\right\}$

The combination of frequency selection and periodic selection is expressed as

$\delta=\left\{\begin{array}{cc}I_{f s e} & K<0.5 \\ I_{\text {nee }} & 0 \text { therwise }\end{array}\right\}$

The difference between the states $5_{3}$ and $5_{1}$ decides the duty cycle ratio $(D)$ as follows:

$D=S_{2} \times S_{1}$

With the above formulation and the battery voltage, the input to the $T_{1}$ is decided as

$T_{1}=\frac{-V_{b}}{(1-D)^{2}}$

$T_{2}=\sqrt{2} * M * T_{1}$

The periodic selector instants are defined by

$T_{r}=T_{1} \sim T_{2}$

With the above selector instant, the voltage across UC prior to selector and after selector are defined by

$V_{b u c 1}=\frac{V_{b u s^{4}} i_{\text {Bus }}}{V_{u r}}$
$V_{\text {buc }}=\frac{V_{b}+T_{T}}{V_{u c}}$

The output for the frequency-periodic controller is expressed as

Output $=V_{\text {buc1 }}+V_{\text {buc }}$

The controller 2 comprised the proportional integral derivative controller with the stator current and motor speed as the inputs to the system. The switching instants (theta 1 and theta2) are computed from these controllers which are given to the Space Vector PWM-based inverter stage prior to the motor. In proposed system, the Permanent Magnet Synchronous Motor (PMSM) is employed.

\subsection{Simulation Analysis}

The effectiveness of the proposed slew mode controller is validated in this section. The voltage across the UC and battery bank are 120 and $60 \mathrm{~V}$. The duty cycle for the pulse generation is 0.25 . The maximum phase voltage for the motor is decided by $180 \mathrm{~V}$. With these specifications, the Table 1 also describes other simulation parameters in detail. 
S. Rajalakshmi et al., International Journal of Advanced Trends in Computer Science and Engineering, 9(3), May - June 2020, 2493 - 2502

Table 1: Simulation Specifications

\begin{tabular}{|c|c|}
\hline Parameter & Value \\
\hline Motor rated power & $2.2 \mathrm{~kW}$ \\
\hline Motor rated voltage & $380 \mathrm{VAC}$ \\
\hline Motor rated current & $3.5 \mathrm{~A}$ \\
\hline Motor rated speed & $1000 \mathrm{RPM}$ \\
\hline Battery voltage & $60 \mathrm{~V}$ \\
\hline Ultracapacitor voltage & $120 \mathrm{~V}$ \\
\hline Inductor & $\mathrm{L} 1=2.9 \mathrm{mH}, \mathrm{L} 2=4 \mathrm{mH}$ \\
\hline Capacitor & $\mathrm{C} 1=\mathrm{C} 2=820 \mu \mathrm{F}$ \\
\hline Switching frequency & $5 \mathrm{kHz}$ \\
\hline
\end{tabular}

With the above settings, the simulation environment is constructed using MATLAB Simulink model, PV source voltage and power and the variations of voltage and current across the elements are investigated from Fig. 5 to 15.

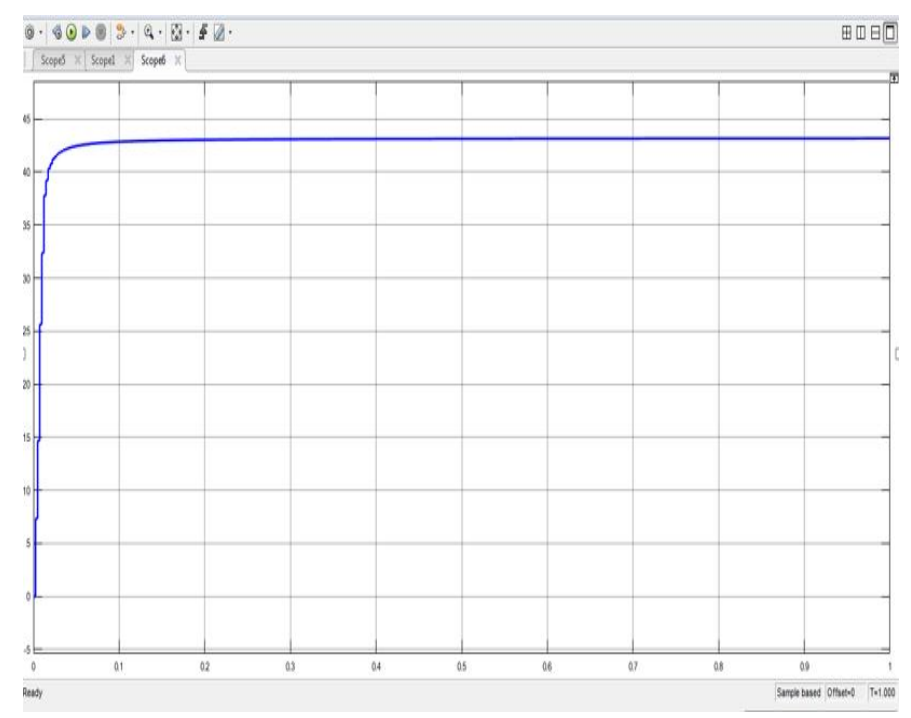

Figure 5: PV Panel Voltage

Figure 5 is the depiction of PV panel voltage. From this evaluation, it is observed that the output power of the proposed DC to DC converter is boosted up.

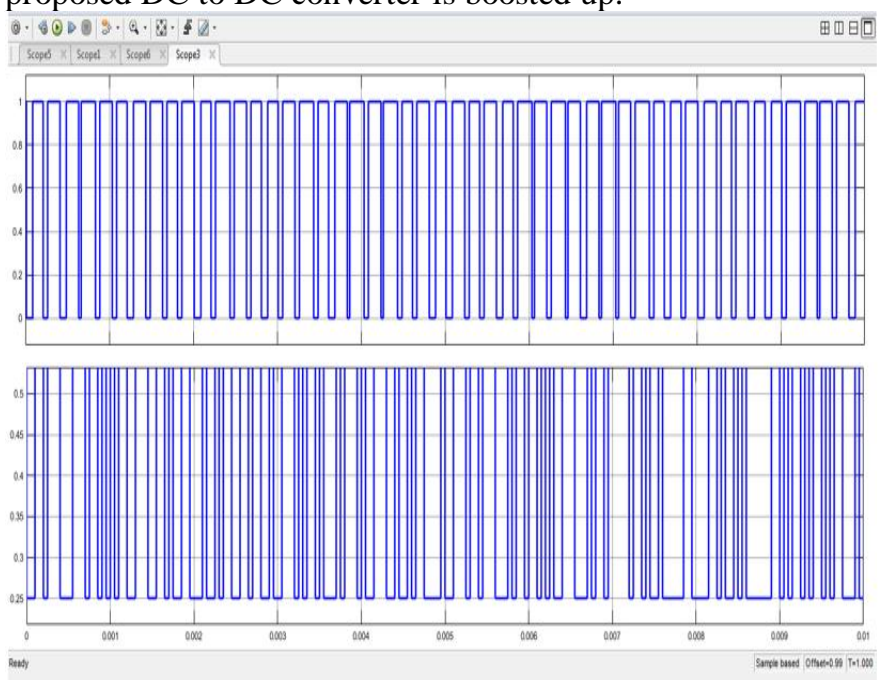

Figure 6: SOS MPPT Technique based Pulse
The control mechanism of SOS based MPPT is deliberated for the regulation of battery charge. This representation is analyzed and the results are shown in figure 6 . It is the duty cycle results which is based on SOS MPPT algorithms. Based on the MPPT SOS algorithm, the duty cycle is diverged regarding voltage and current to attain the maximum power. From this duty cycle, the pulses are taken which is used in the DC to DC converter switches.

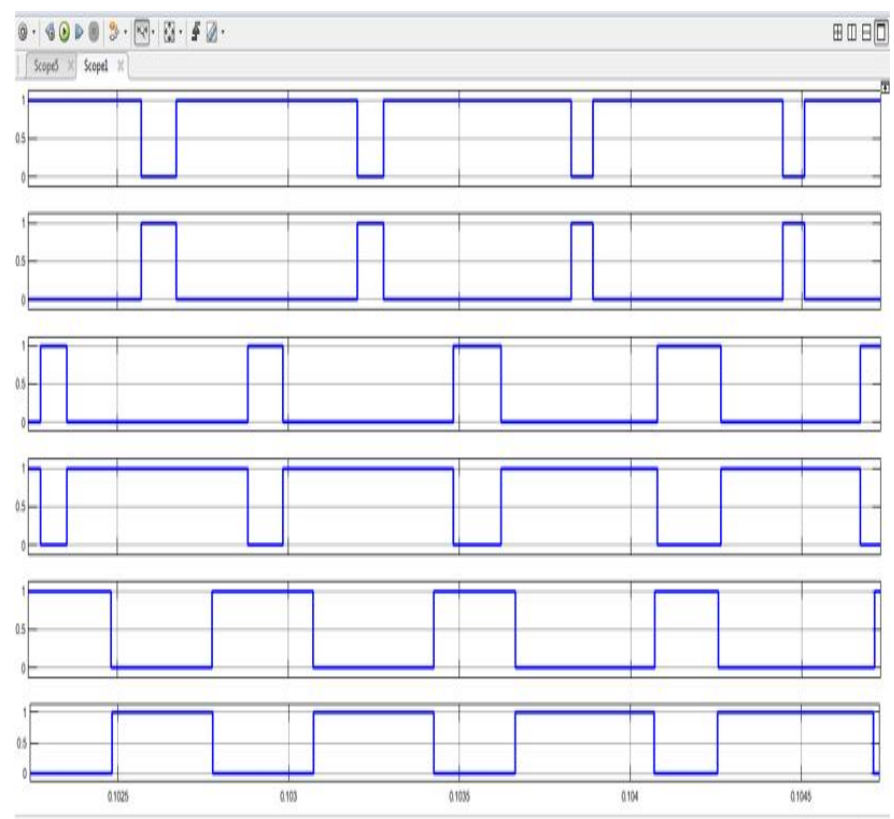

Figure 7: Switching Pulse for Inverter

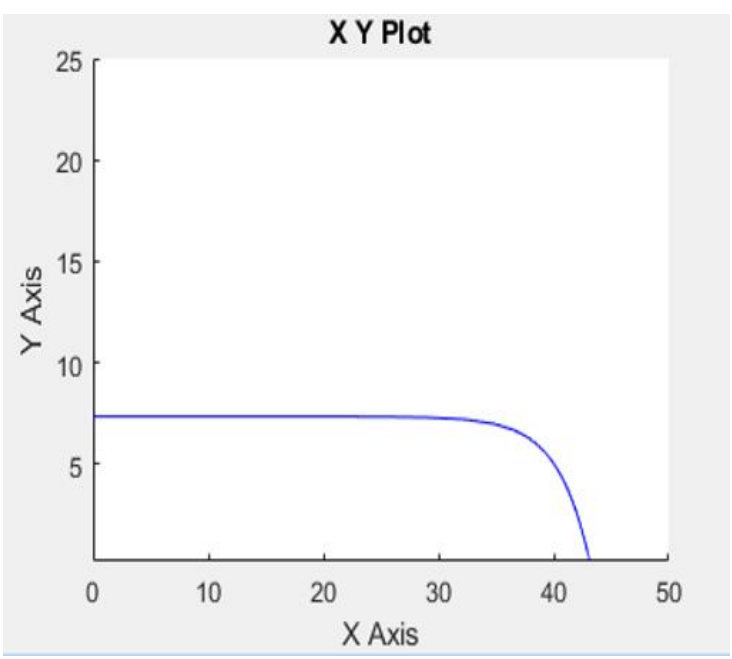

Figure 8: I-V character

Figure 8 shows the I-V characteristics of the system performance which varies and fluctuates. 


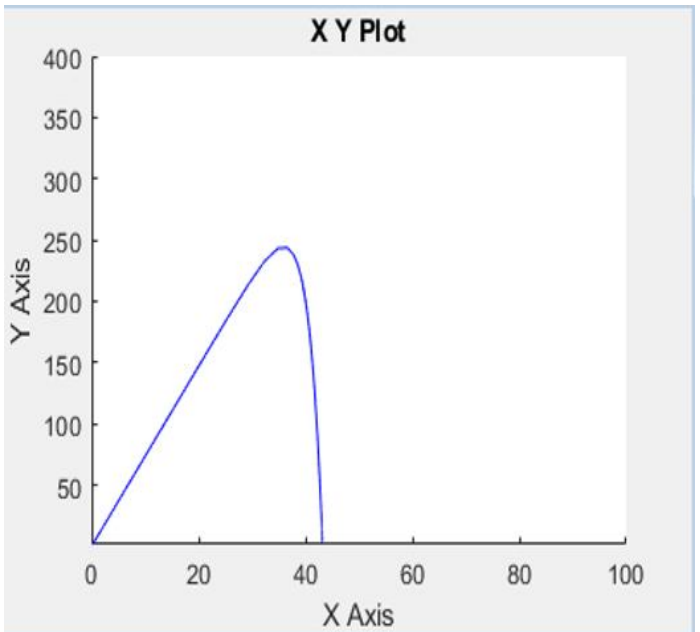

Figure 9: PV Power

Figure 9 is the PV power analysis and the representation of the outcomes are shown. It is the outcome of PV panel power proposed work. The curve specifies the solar panel power in KW. Depending on the current and voltage that acquired from PV was utilized for varying duty cycle.

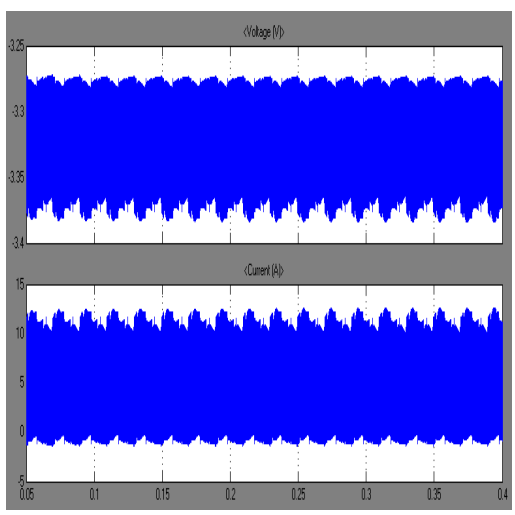

Figure 10: Battery voltage and current

Figure 10 shows the battery voltage and current performance.

The variations are monitored and plotted as shown above.

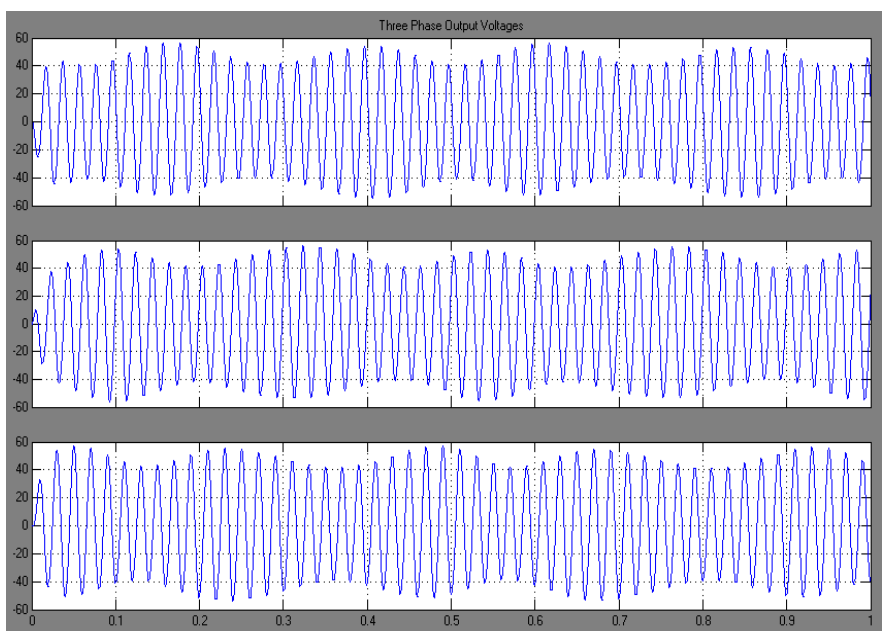

Figure 11: Inverter output voltage
Inverter output voltage is shown in figure 11 . The variations are plotted to show the effectiveness of proposed voltage variation of the inverter.

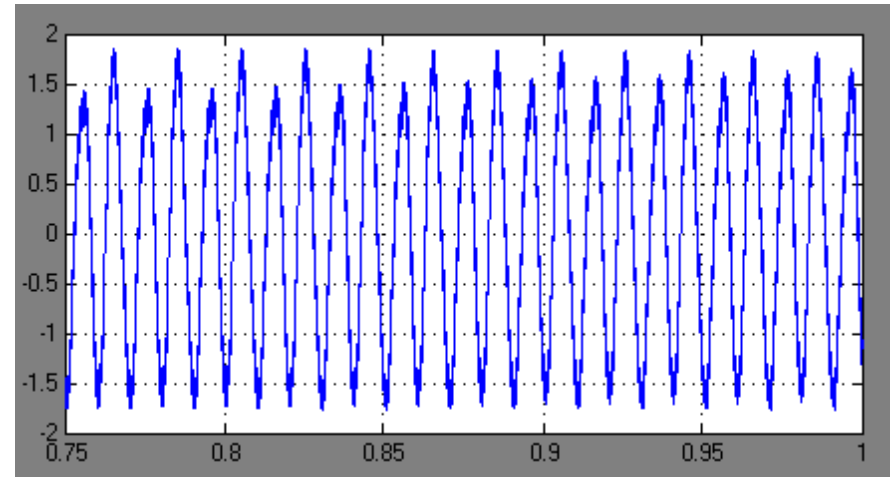

(a)

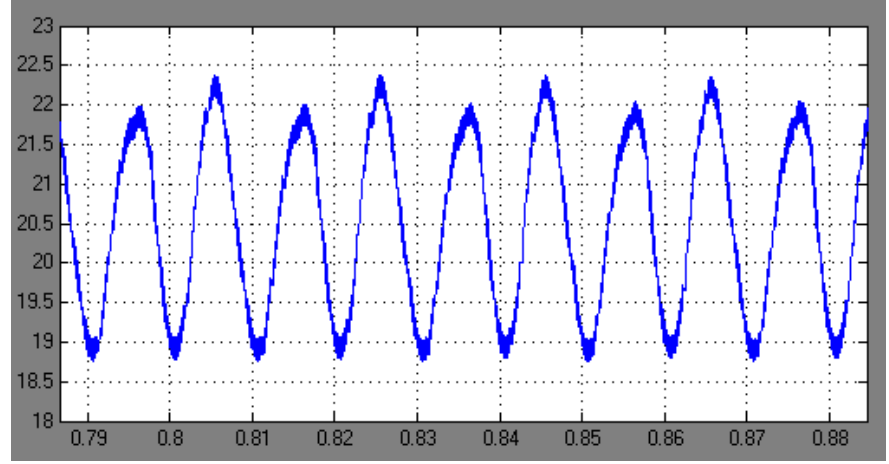

(b)

Figure 12: Voltage across (a) L1 and (b) C2

The variation of voltage across L1 and C2 are analyzed and the performance outcomes are plotted in figure 12 .

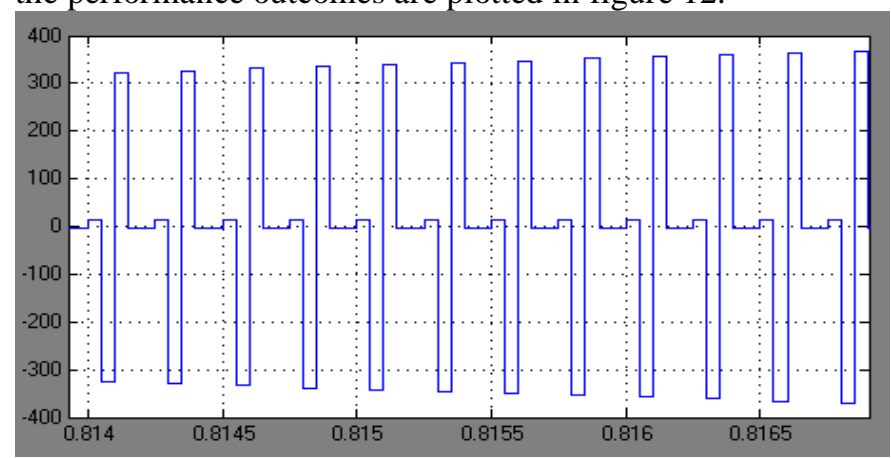

(a)

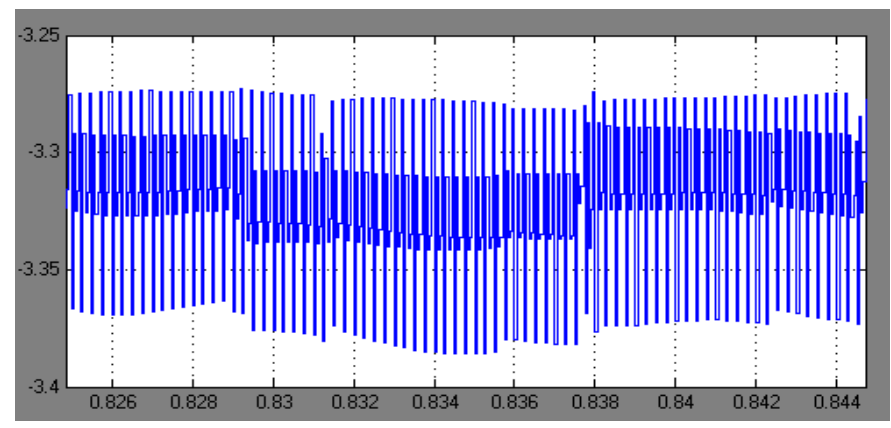

(b)

Figure 13: Voltage across (a) L2 and (b) C1 
The variation of voltage across $\mathrm{L} 2$ and $\mathrm{C} 1$ is depicted as plotting representation in figure 13.

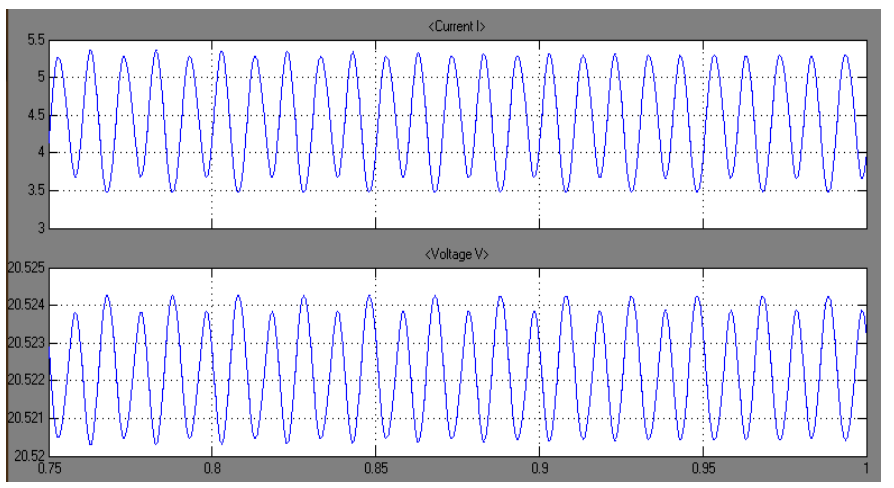

Figure 14: Current and voltage across ultracapacitor

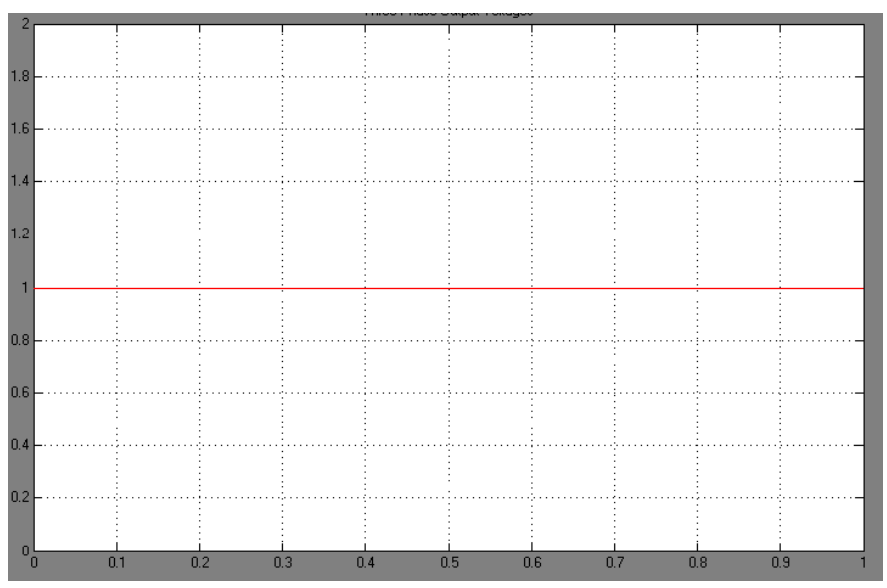

Figure 15: Power Factor

From the experimental results, we observed that the proposed OSMC topology preserves the energy across the battery by current controlling function. The maintenance of voltage and current stability across the battery in Fig. 10 depicts the controlling of current flow across the ultra-capacitor which provides the constant power factor as shown in Fig. 15.

\section{CONCLUSION}

This paper highlighted the issues in the controlling topologies for the bidirectional converters deployed in the hybrid vehicle applications to store the energy levels. The integration of inverter-converter topologies into the hybrid vehicle applications assured the stable output energy levels across the load. The disturbances in the output voltage levels are large with increase in harmonic content due to the non-linear loads. The proper control topology is the major requirement for the controllable voltage generation across the diverse load sizes. This paper proposed the optimal slewing mode converter (OSMC) topology which generated the gate control signals to the switches present in the Bi-directional Converter (BC). The current-controlled pulse generation assured the dynamic response and the robustness irrespective of the climate conditions. The integration of frequency and periodic sectors to the bidirectional converter with the optimization results in dynamic power regulation and battery stress. The simulation in both time and frequency sector investigated the performance of proposed topology in hybrid energy storage applications.

\section{REFERENCES}

[1] B. Liu and S. Duan, "Energy efficiency evaluation of building integrated photovoltaic systems with different power configurations," Simulation Modelling Practice and Theory, vol. 29, pp. 93-108, 2012.

https://doi.org/10.1016/j.simpat.2012.07.014

[2] J.-M. Shen, H.-L. Jou, and J.-C. Wu, "Novel transformerless grid-connected power converter with negative grounding for photovoltaic generation system," IEEE Transactions on Power Electronics, vol. 27, pp. 1818-1829, 2012.

https://doi.org/10.1109/TPEL.2011.2170435

[3] J. I. Leon, S. Kouro, L. G. Franquelo, J. Rodriguez, and $\mathrm{B}$. $\mathrm{Wu}$, "The essential role and the continuous evolution of modulation techniques for voltage-source inverters in the past, present, and future power electronics," IEEE Transactions on Industrial Electronics, vol. 63, pp. 2688-2701, 2016. https://doi.org/10.1109/TIE.2016.2519321

[4] F. Blaabjerg and K. Ma, "Future on power electronics for wind turbine systems," IEEE Journal of Emerging and Selected Topics in Power Electronics, vol. 1, pp. 139-152, 2013.

https://doi.org/10.1109/JESTPE.2013.2275978

[5] J. Yin, S. Duan, and B. Liu, "Stability Analysis of Grid-Connected Inverter With LCL Filter Adopting a Digital Single-Loop Controller With Inherent Damping Characteristic," IEEE Transactions on Industrial Informatics, vol. 9, pp. 1104-1112, 2013. https://doi.org/10.1109/TII.2012.2222424

[6] S. Vazquez, J. I. Leon, L. G. Franquelo, J. Rodriguez, H. A. Young, A. Marquez, et al., "Model predictive control: A review of its applications in power electronics," IEEE Industrial Electronics Magazine, vol. 8, pp. 16-31, 2014.

https://doi.org/10.1109/MIE.2013.2290138

[7] Z.-X. Zou, K. Zhou, Z. Wang, and M. Cheng, "Frequency-adaptive fractional-order repetitive control of shunt active power filters," IEEE Transactions on Industrial Electronics, vol. 62, pp. 1659-1668, 2015.

[8] V. R. Pandi, A. Al-Hinai, and A. Feliachi, "Coordinated control of distributed energy resources to support load frequency control," Energy Conversion and Management, vol. 105, pp. 918-928, 2015.

https://doi.org/10.1016/j.enconman.2015.08.046 
S. Rajalakshmi et al., International Journal of Advanced Trends in Computer Science and Engineering, 9(3), May - June 2020, 2493 - 2502

[9] F. Carnielutti, H. Pinheiro, and C. Rech, "Generalized carrier-based modulation strategy for cascaded multilevel converters operating under fault conditions," IEEE Transactions on Industrial Electronics, vol. 59, pp. 679-689, 2012. https://doi.org/10.1109/TIE.2011.2157289

[10] T.-F. Wu, C.-L. Kuo, L.-C. Lin, and Y.-K. Chen, "DC-bus voltage regulation for a DC distribution system with a single-phase bidirectional inverter," IEEE Journal of Emerging and Selected Topics in Power Electronics, vol. 4, pp. 210-220, 2016.

[11] T.-F. Wu, C.-L. Kuo, K.-H. Sun, Y.-K. Chen, Y.-R. Chang, and Y.-D. Lee, "Integration and operation of a single-phase bidirectional inverter with two buck/boost MPPTs for DC-distribution applications," IEEE Transactions on Power Electronics, vol. 28, pp. 5098-5106, 2013. https://doi.org/10.1109/TPEL.2013.2245681

[12] T.-F. Wu, L.-C. Lin, N. Yao, Y.-K. Chen, and Y.-C. Chang, "Extended Application of D-\$ $\$ \backslash$ bf $\Sigma\} \$$ Digital Control to a Single-Phase Bidirectional Inverter With an LCL Filter," IEEE Transactions on Power Electronics, vol. 30, pp. 3903-3911, 2015.

[13] S.-M. Chen, T.-J. Liang, L.-S. Yang, and J.-F. Chen, "A safety enhanced, high step-up DC-DC converter for AC photovoltaic module application," IEEE Transactions on power electronics, vol. 27, pp. 1809-1817, 2012.

[14] P. Xuewei and A. K. Rathore, "Current-fed soft-switching push-pull front-end converter-based bidirectional inverter for residential photovoltaic power system," IEEE Transactions on Power Electronics, vol. 29, pp. 6041-6051, 2014. https://doi.org/10.1109/TPEL.2014.2301495

[15] C. Wang, Y. Mi, Y. Fu, and P. Wang, "Frequency control of an isolated micro-grid using double sliding mode controllers and disturbance observer," IEEE Transactions on Smart Grid, pp. 1-1, 2016.

[16] R. L. de Araujo Ribeiro, C. C. de Azevedo, and R. M. de Sousa, "A robust adaptive control strategy of active power filters for power-factor correction, harmonic compensation, and balancing of nonlinear loads," IEEE Transactions on Power Electronics, vol. 27, pp. 718-730, 2012.

[17] M. Merai, M. Naouar, I. Slama-Belkhodja, and E. Monmasson, "FPGA-based Space Vector Delta Modulation Current Controller for Grid connected Converters," in Industrial Electronics Society, IECON 2016-42nd Annual Conference of the IEEE, 2016, pp. 2301-2306.

[18] S. Vazquez, A. Marquez, R. Aguilera, D. Quevedo, J. I. Leon, and L. G. Franquelo, "Predictive optimal switching sequence direct power control for grid-connected power converters," IEEE Transactions on Industrial Electronics, vol. 62, pp. 2010-2020, 2015.
[19] J. Linares-Flores, A. H. Mendez, C. Garcia-Rodriguez, and H. Sira-Ramirez, "Robust nonlinear adaptive control of a "boost" converter via algebraic parameter identification," IEEE Transactions on Industrial Electronics, vol. 61, pp. 4105-4114, 2014. https://doi.org/10.1109/TIE.2013.2284150

[20] J. Liu, S. Vazquez, L. Wu, A. Marquez, H. Gao, and L. G. Franquelo, "Extended State Observer-Based Sliding-Mode Control for Three-Phase Power Converters," IEEE Transactions on Industrial Electronics, vol. 64, pp. 22-31, 2017.

[21] P. Kanjiya, V. Khadkikar, and H. H. Zeineldin, "A noniterative optimized algorithm for shunt active power filter under distorted and unbalanced supply voltages," IEEE Transactions on Industrial Electronics, vol. 60, pp. 5376-5390, 2013.

[22] M. Badoni, A. Singh, and B. Singh, "Comparative performance of wiener filter and adaptive least mean square-based control for power quality improvement," IEEE Transactions on Industrial Electronics, vol. 63, pp. 3028-3037, 2016. https://doi.org/10.1109/TIE.2016.2515558

[23] M. K. Modi, S. Venugopal, and G. Narayanan, "Space vector-based analysis of overmodulation in triangle-comparison based PWM for voltage source inverter," Sadhana, vol. 38, pp. 331-358, 2013. https://doi.org/10.1007/s12046-013-0149-x

[24] K. Kumar and K. Sivakumar, "A quad two-level inverter configuration for four-pole induction-motor drive with single DC link," IEEE Transactions on Industrial Electronics, vol. 62, pp. 105-112, 2015. https://doi.org/10.1109/TIE.2014.2327577

[25] H. Liu and F. Li, "A novel high step-up converter with a quasi-active switched-inductor structure for renewable energy systems," IEEE Transactions on Power Electronics, vol. 31, pp. 5030-5039, 2016. 